\title{
0 Comportamento da Camada Superficial das Misturas Poliméricas nos Ciclos de Estiramento/Relaxamento. 1. Estiramento
}

\author{
Marianna M. Gorelova, Ailton S. Gomes, Nadir B. Sanches, Esperanza A. V. Roldan, Regina Célia R. Nunes \\ Instituto de Macromoléculas Professora Eloisa Mano, UFRJ \\ Alexander J. Pertsin e Ilia 0. Volkov \\ Institute of Organo-Element Compounds, Russian Academy of Science, Moscow, Russia
}

Resumo: O efeito do estiramento uniaxial na superfície de vários compósitos (misturas diluídas de copolímero polietersulfona/polidimetilsiloxano em policloropreno) foi estudado através do método de espectroscopia de fotoelétrons excitados por raios-X. A superfície inicial das misturas não estendida foi beneficiada pelo copolímero (75-93\%). O estiramento acarretou uma queda da segregação superficial do copolímero. A comparação dos dados experimentais com o estiramento teórico, para diversos modelos de extensão da camada superficial, permitiu concluir que o copolímero com o bloco de polisulfona curto, acompanha exatamente o estiramento da matriz, ao passo que o copolímero com o bloco de polisulfona longo se atrasa um tanto e se estende um tanto menos.

Palavras-chave: Superficie, XPS, misturas poliméricas, deformação.

\section{The surface behavior of polymeric blends upon stretching/contraction 1. The stretching process}

Abstract: The effect of uniaxial stretching on the surface composition of blends of poly(dimethyl siloxane/poly(sulfone) block copolymers in polychloroprene is studied using X-Ray photoelectron spectroscopy. The surface of the initial (unstretched) blends was covered by copolymer overlayer. The stretching lead to a substantial drop of the copolymer surface segregation. The comparison of the experimental data with different models of deformation leads to the conclusion that copolymer overlayer with short segment of poli(sulfone) follows the deformation of CR matrix on stretching; however an overlayer with long poli(sulfone) segment is stretched with delay.

Keywords: Surface, XPS, polymer blends, deformation.

\section{Introdução}

A investigação da composição da superfície dos polímeros é essencial na área de desenvolvimento e aplicação de novos materiais poliméricos. Propriedades como adesão, umedecimento, resistência à abrasão e biocompatibilidade, são influenciadas exclusivamente pela composição de algumas monocamadas superficiais, e independem, ou dependem pouco, do interior do produto. Isto significa que, muitas vezes, não há necessidade de mudar o polímero como um todo, mas apenas sua superfície, para que determinadas especificações sejam atingidas. Por isso hoje os estudos da estrutura química das camadas superficiais de compósitos poliméricos e da modificação da superfície dos polímeros são temas tão atuais $^{[1-8]}$.

Quando um material polimérico está sendo usado, sua superfície exposta fica, antes de mais nada, sujeita à influência de fatores externos: atrito com outros materiais, contato com reagentes, oxidação, radiação, etc., levando ao envelhecimento e, por consequência, à sua destruição ${ }^{[9]}$. Além de todos esses fatores, a estrutura das camadas superficiais é

Autor para correspondência: Marianna M. Gorelova, UFRJ/IMA, Cx.Postal 68.525, CEP 21945-970, Rio de Janeiro, R. J., E-mail: mgorelova@ima.ufr..br 
particularmente sensível à deformação mecânica. Isto se deve a duas causas. Primeiro, para a camada superior, o alongamento ou a compressão se operam não só sob macrodeformações de todo material polimérico, mas também quando se operam simplesmente apenas pequenas flexões. Por exemplo, quando se dobra um tubo polimérico, a sua superfície externa sofre um forte alongamento, ao passo que a sua superfície interna se comprime. A segunda causa consiste em que a deformação, causando o aumento da área da superfície, causa, paralelamente, mistura da camada superficial com as camadas subsuperficiais. Quando a composição da superfície do polímero é diferente da volumétrica (tal como acontece em quase todos os compósitos ou nos polímeros com a superfície modificada $^{[2-4,7]}$ ), a deformação leva a mistura das camadas com diferentes composições. Assim, quando tencionamos o polímero, mesmo as deformações, os alongamentos e as flexões insignificantes podem provocar grandes modificações da composição da estrutura das camadas superficiais.

Neste trabalho é investigada a superfície da mistura de elastômero, que serve como uma base facilmente deformável, à qual se juntou um tensoativo. Esta adição cria na superfície uma camada rica em aditivo, que, em geral, graças às suas propriedades mecânicas, pode ser um polímero vítreo, não elastomérico, ou permanecer num estado viscosofluido. Durante a deformação, a camada superficial pode deformar-se simultaneamente com a matriz elástica, pode, ao contrário, não mudar em nada as suas dimensões (neste caso, o estiramento se efetuará exclusivamente por conta da base elástica) e ainda podem ocorrer situações intermediárias - a camada superficial, até certo ponto, acompanha a expansão da matriz. É evidente que, a conduta do componente tensoativo depende não só das propriedades do polímero que foi acrescentado, mas também do grau de compatibilidade dos componentes da composição. Se o aditivo é compatível com a base e se eles, por conseguinte, estão misturados ao nível molecular, o mais provável é que eles irão estirar-se também de modo homogêneo. Se, ao contrário, forem incompatíveis, ocorrerá uma grande separação de fase, é de se esperar que o aditivo se comporte de um modo mais ou menos autônomo e não se estenda junto com a base elástica. No final todos os fenômenos conhecidos que acompanham a deformação mecânica dos polímeros - tais como a orientação dos ele- mentos estruturais submoleculares, a recristalização, o aumento local da mobilidade molecular, o aumento de volume livre, microfendimento e etc., podem influir de um ou outro modo sobre a composição superficial dos polímeros nos ciclos estiramento/relaxamento.

Nos trabalhos anteriores ${ }^{[10,11]}$, investigamos a conduta da camada superficial fina do elastômero CR (policloropreno), modificada por aditivos de siloxano ativos na superfície, no processo de alongamento e relaxamento. O revestimento fino de Poli(dimetilsiloxano) (PDMS) na superfície de CR era obtido por meio do acréscimo à $\mathrm{CR}$-matriz de pequenas quantidades de modificador, o qual, por força de energia superficial baixa do siloxano, segregava para a superfície do elastômero, formando uma camada modificada. As pesquisas foram feitas para um elastômero modificado por PDMS de diferentes massas moleculares. Constatamos que a deformação exerce uma grande influência sobre a composição e a estrutura da camada superficial do elastômero modificado. Assim é que nas composições de CR+PDMS, no processo de estiramento a concentração de siloxano na superfície, cai na vertical, ao passo que quando a amostra retorna às dimensões iniciais, o revestimento inicial de siloxano não se reconstitui e a superfície do CR fica parcialmente desnudada.

O método de pesquisa da estrutura química da superfície no presente trabalho é XPS (X-Ray Photoelectron Spectroscopy) - espectroscopia de fotoelétrons excitados por raios-X, extremamente sensível à estrutura química da superfície do polímero $^{[12-18]}$. XPS proporciona os dados sobre a composição e a estrutura da camada superficial de 5 ou menos monocamadas - camada onde se passam todas mudanças principais por ocasião da deformação das camadas segregadas na superfície. XPS oferece a análise quantitativa dos grupos funcionais, muito importante para os polímeros, já que uma análise elementar seria de pouca validade. XPS prova só informação integral sobre concentração dos elementos e grupos químicos em toda camada analisada. Todavia, justamente no caso dos polímeros deformados, apesar de falta de informação exata sobre a distribuição lateral dos componentes na superfície, XPS fornece muitas informações sobre a conduta desses componentes nos processos de estiramento e relaxamento de amostra . 
No presente trabalho realizamos as investigações com XPS da camada superficial dos compósitos de matriz elástica - policloropreno, e do copolímero de poli(bisphenol A sulfona)/polidemitelsiloxana (PES/ PDMS), o qual pode ser considerado um aditivo modificador da superfície ${ }^{[7-8]}$. Para avaliar o papel de flexibilidade da molécula do modificador no comportamento da camada superficial, nós escolhemos os copolímeros com diferentes pesos moleculares de bloco flexível (siloxano) e diferentes blocos rígidos (polisulfona).

\section{Experimental}

Os dois copolímeros de PES/PDMS utilizados para preparação das misturas foram perfeitamente alternados, diferindo nos comprimentos dos blocos individuais, respectivamente: 44000/2500 e 3500/2500. Homopolímero policloropreno (CR) Neopreno ${ }^{\circledR}$ (Du Pont) era um polímero comercial, não reticulado ${ }^{[19]}$.

Composições de CR + PES/PDMS foram preparados a partir da mistura de soluções diluídas dos componentes em clorofórmio, solvente comum a todos, em quantidades adequadas para formar a composição pretendida. A faixa de composições preparada foi de 0,5 a 2,5\% em peso do copolímero. Os filmes para os experimentos de deformação e medidas de XPS foram obtidos por vazamento destas soluções sobre celofane devidamente esticado, com posterior evaporação do clorofórmio à temperatura ambiente. Para análise foi usada a face das amostras, que formou-se ao lado do ar.
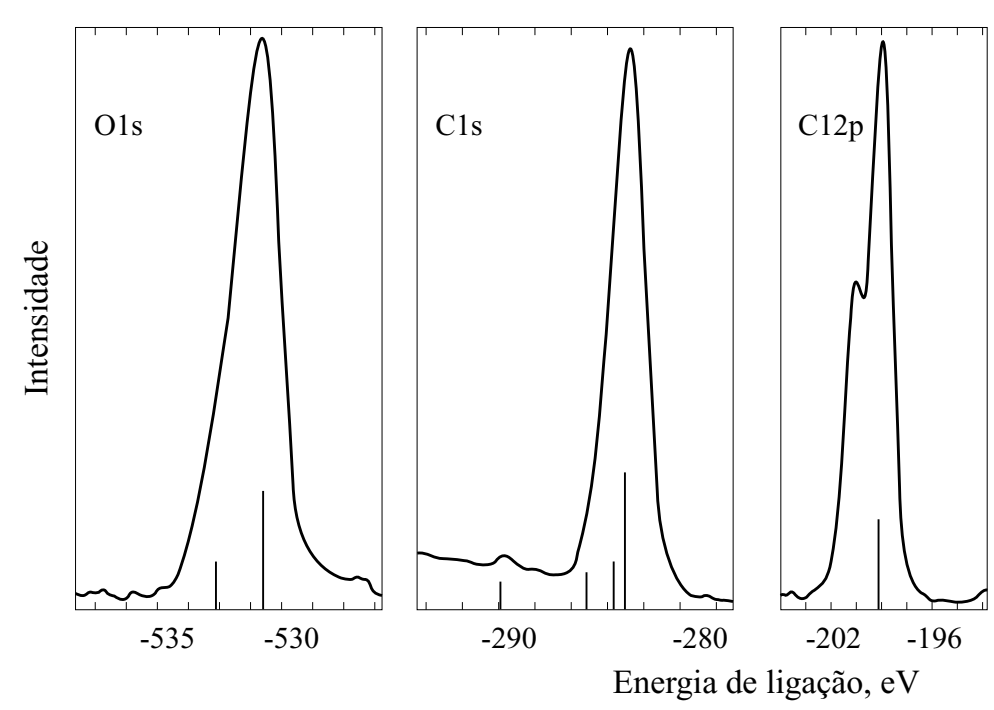

Os experimentos de estiramento foram realizados em filmes de corpos de prova retangulares de 20x70x0,3 mm. O estiramento foi feito à temperatura ambiente, à velocidade de $0,1 \mathrm{~mm} / \mathrm{seg}$. Após o estiramento ao tamanho desejado o filme foi fixo colando-a sobre suporte metálico .

A espectroscopia de fotoelétrons excitados por raios-X (XPS) foi realizada com um espectromicroscópio Kratos XSAM-800, usando como fonte excitadora a radiação $K \alpha$ do magnésio. A pressão na câmara da amostra era de $10^{-9}-10^{-10}$ Torr. O feixe de raios- $X$ usado tinha potência média (12 $\mathrm{kV}, 5 \mathrm{~mA}$ ), o qual não produz danos detectáveis nas amostras. A correção na escala de valores de energia de ligação foi feita definindo em $285 \mathrm{eV}$ para a menor energia de ligação da emissão $\mathrm{C} 1 \mathrm{~s}$. A composição da superfície das misturas foi calculada a partir das intensidades integrais dos sinais Si2p, $\mathrm{S} 2 \mathrm{p}, \mathrm{e} \mathrm{Cl} 2 \mathrm{p}$ conforme descrito anteriormente ${ }^{[3]}$. A composição da superfície da fase do copolímero foi também determinada através de outro modo independente, baseado na resolução do espectro do $\mathrm{O} 1 \mathrm{~s}$ nas contribuições dos átomos de oxigênio dos blocos PDMS e PES: O-Si $(532,6), \mathrm{O}=\mathrm{S} \quad(532,0), \mathrm{O}-\mathrm{Ph}$ $(533.6 \mathrm{eV})$.

Para julgar a presença de um gradiente de concentração na região próxima à superfície, os espectros foram adquiridos tanto a ângulos $\theta$ de $0^{\circ}$ como de $60^{\circ}$ (ângulo $\theta$ é ângulo entre normal a superfície da amostra e direção ao detetor dos fotoeletrons), os quais correspondem a uma profundidade de análise de 50 e $25 \AA$, respectivamente.
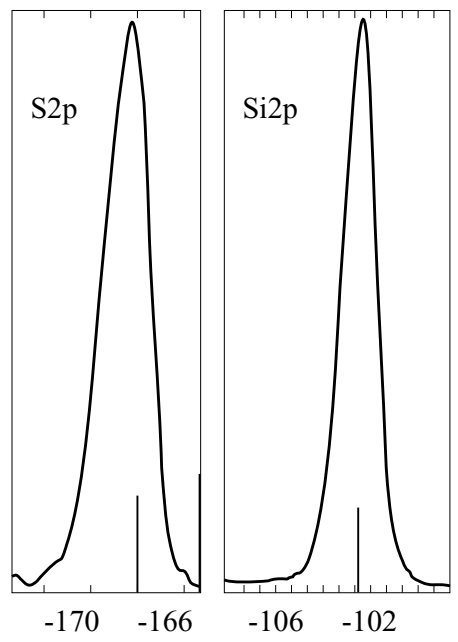

Figura 1. Espectro de XPS da mistura de CR com 1\%PES/PDMS(3500/2500). 


\section{Resultados e Discussão}

\section{Composição da superfície das amostras antes do estiramento.}

Antes de investigar o comportamento da camada superficial das amostras deformadas, a composição da superfície das amostras iniciais foi detalhadamente estudada. Na Figural está apresentado o espectro fotoeletrônico (espectro de XPS) tipico para a mistura de CR com o copolímero PES/ PDMS. O espectro apresenta a superposição dos espectros de três componente: CR, PES e PDMS.

$\mathrm{O}$ espectro de $\mathrm{CR}$ puro contem 2 linhas principais: carbono $\mathrm{C} 1 \mathrm{~s}$ e cloro $\mathrm{Cl} 2 \mathrm{p}$. A linha de carbono contém 2 componentes que correspondem a carbono ligado só com outro átomo de carbono (grupo C-C) com energia de ligação $\mathrm{E}_{\mathrm{BE}}=285,0 \mathrm{eV}$, e carbono ligado a cloro (grupo C-Cl) com energia de ligação $\mathrm{E}_{\mathrm{BE}}=286,3 \mathrm{eV}$. A relação das intensidade dos componentes do pico de carbono corresponde à relação de quantidade de átomos de carbono em grupos C-C e C-Cl (5:1). Como a cadeia de CR possui as ligações insaturadas, no lado de altas energias de ligação do pico $\mathrm{C} 1 \mathrm{~s}$, se apresenta um satélite "shake-up " $\left(\mathrm{E}_{\mathrm{BE}}=292 \mathrm{eV}\right)$ com intensidade 3\% da intensidade de C1s. ( O satélite "shake-up" surge devido aos fotoelétrons que perderam a sua energia por causa da reorganização da camada de valência: durante a passagem do elétron de valencia da camada eletrônica preenchida (nível - $\pi$ ) para a camada não preenchida (nível $-\pi^{*}$ ).) O pico de cloro $\mathrm{Cl} 2 \mathrm{p}$ fica em $200.7 \mathrm{eV}$. (Por causa de desdobramento spin-orbital, os picos $2 p$ contém dois componentes: $2 \mathrm{p} 1 / 2$ e $2 \mathrm{p} 3 /$ 2.). Como o elastômero usado nos experimentos era comercial, sem algum tratamento adicional, na superfície estão presentes pequenas contaminações de oxigênio, o que leva ao aparecimento do fraco sinal de oxigênio $\mathrm{O} 1 \mathrm{~s}$ no espectro.

$\mathrm{O}$ espectro de PES contém os picos de $\mathrm{C} 1 \mathrm{~s}, \mathrm{O} 1 \mathrm{~s} \mathrm{e}$ enxofre S2p. Os componentes do pico $\mathrm{C} 1$ s correspondem aos grupos de carbono: - $\mathrm{CH}(285.0 \mathrm{eV})$, -CS $(285.6 \mathrm{eV}),-\mathrm{CO}(286.6 \mathrm{eV})$ e shake-up satélite $(292 \mathrm{eV}, 14 \%$ do pico $-\mathrm{CH})$. O pico O1s pode ser facilmente desdobrado em 2 picos: $\mathrm{C}-\mathrm{O}-\mathrm{C}$ (533.6) e $\mathrm{O}=\mathrm{S}$ (531.9). O pico de S2p fica em $1679 \mathrm{eV}$.

O espectro de PDMS contém picos simples de C1s (285.0 eV), O1s (532.6 eV) e silício Si2p (102.5 eV).

O espectro do elastômero modificado (Figura 1), que refere-se a uma das misturas de CR com o copolímero PES/PDMS, apresenta uma superposição complicada desses três espectros, onde a contribuição de cada um deles no espectro corresponde à sua concentração na camada superficial. Todavia, os 3 polímeros que participam da composição são bem distinguíveis no espectro, porque cada bloco possui o seu elemento típico : CR - Cl, PDMS - Si e PES $\mathrm{S}$. Além disso, para obter informações suplementares é muito cômodo o fato de que o oxigênio na PES $(\mathrm{O}=\mathrm{S})$ é diferente do oxigênio no PDMS, ao passo que no $\mathrm{CR}$ o oxigênio praticamente está ausente. $\mathrm{O}$ satélite "Shake-up" na linha de carbono, indica a presença de grupos polisulfona (o "shake-up" de cloropreno é fraco demais para aparecer no espectro das misturas).

A relação das intensidades integrais dos picos permite obter, da análise quantitativa dos espectros XPS, a concentração de cada átomo na camada superficial; a relação das intensidades das componentes de cada pico fornece a concentração de cada grupo químico em porcentagem atômica. A concentração dos 3 componentes na camada superficial da mistura (CR, PDMS e PES) também pode ser avaliada em porcentagem atômica. Por exemplo \% atômica de CR mostra quantos átomos de policloropreno entre 100 átomos de todos os tipos presentes na superfície. $\mathrm{O}$ valor da \%CR corresponde à parte da área da superfície ocupada pelo cloropreno. As formulas usadas para avaliar os percentuais atômicos dos três componentes das composições são seguintes: $\% \mathrm{CR}=5 \% \mathrm{Cl} 2 \mathrm{p} ; \% \mathrm{PDMS}=4 \% \mathrm{Si} 2 \mathrm{p} ; \% \mathrm{PES}=32 \%$ $\mathrm{S} 2 \mathrm{p}$, onde coeficiente entre $\%$ de polímero e $\%$ de átomo é fácil obter a partir da formula química do polímero.

$\mathrm{Na}$ Tabela 1 estão apresentados os resultados da analise quantitativa dos espectros XPS das amostras iniciais não estendidas.

A tenção superficial de PDMS, PES e CR equivale a 20,35 e $44 \mathrm{din} / \mathrm{cm}$, por isso é de se esperar que a superfície da composição seja beneficiada pelo copolímero, sendo que o próprio copolímero será orientado com siloxano à superfície, ao passo que a polisulfona, para o fundo. De acordo com os dados da Tabela 1, em todas as composições CR + PES/PDMS ocorre uma intensa segregação superficial de copolímero. Assim acréscimo de apenas $1 \%$ de copolímero 44000/2500 em volume de CR leva a $93 \%$ dele para a superfície, e apenas $7 \%$ da superfície fica ocupada pela matriz elastomérica.

A analise de XPS das composições sob diferentes ângulos permite avaliar a topografia da su- 
Tabela 1. A concentração dos componentes CR, PES e PDMS na superfície das amostras iniciais, não estendidas, para profundidade de análise de 50 e $25 \AA$.

\begin{tabular}{|c|c|c|c|c|c|c|c|}
\hline \multirow{2}{*}{$\mathbf{N}$} & \multirow[t]{2}{*}{ Composição da Mistura } & \multicolumn{3}{|c|}{$\begin{array}{c}\% \text { atômico na camada } \\
\text { superficial de } 50 \AA\end{array}$} & \multicolumn{3}{|c|}{$\begin{array}{c}\% \text { atômico na camada } \\
\text { superficial de } 25 \AA\end{array}$} \\
\hline & & $\mathbf{C R}$ & PDMS & PES & $\mathbf{C R}$ & PDMS & PES \\
\hline 1 & $\mathrm{CR}+1 \%(3500 / 2500)$ & 13 & 49 & 38 & 12 & 62 & 28 \\
\hline 2 & $\mathrm{CR}+1 \%(44000 / 2500)$ & 7 & 28 & 67 & 7 & 40 & 55 \\
\hline
\end{tabular}

perfície. Como na camada superficial de todas as misturas está presente o cloropreno, concluímos que o copolímero não forma uma camada contínua. A comparação de dados na Tabela 1 da coluna da esquerda (camada de $50 \AA)$ e da direita $(25 \AA)$ mostra que a correlação $\mathrm{CR} /$ copolímero não muda com a profundidade. Isso significa que o $\mathrm{CR}$ e copolímero formam blocos verticais e a profundidade desses blocos é maior do que a profundidade da analise $(50 \AA)$.

Para todas as misturas, dentro da fase do copolímero se opera uma forte segregação do siloxano na direção da superfície, uma vez que a analise angular demonstra um forte gradiente do PDMS em direção à superfície. Ao mesmo tempo, a concentração de PES é menor na camada de $25 \AA ̊$ do que na camada de 50 Å.

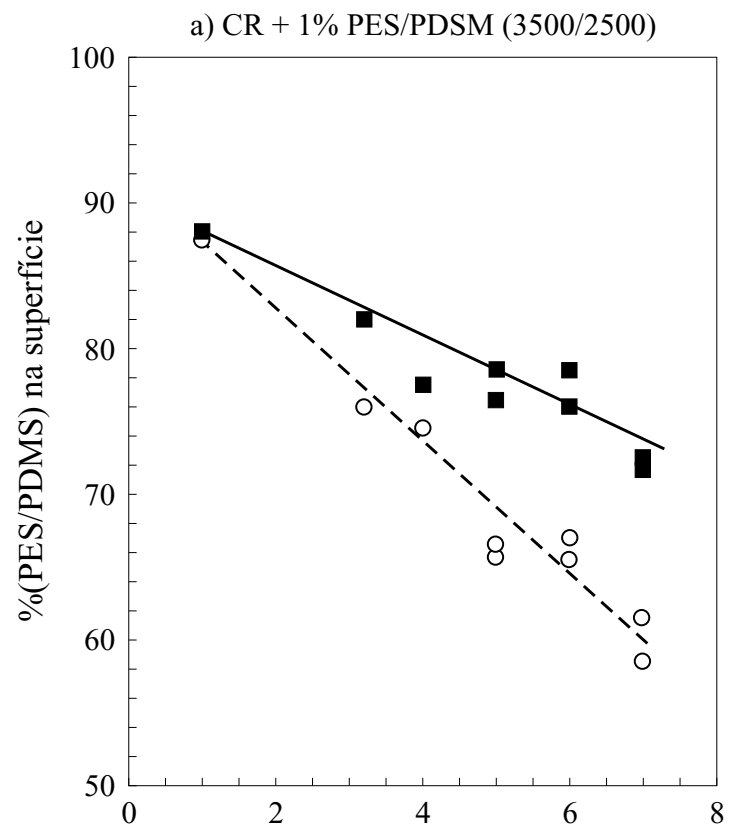

\section{Composição da superfície das amostras estendidas.}

Os filmes das composições 1-5 foram estendidos até $\alpha$ vezes $(\alpha=2,3,4,5,6,7)$ com velocidade lenta, foram fixadas no estado estendido e foram logo analisadas. As mudanças da composição na superfície podem ser estudadas pelo valor da concentração de copolímero $\%$ (PES/PDMS) ou pela concentração de elastômero, \% CR como função do grau de estiramento a da amostra. As mudanças na orientação dos blocos dentro do copolímero podem ser avaliadas pela relação entre \% PES / \% PDMS.

Na Figura 2 está apresentada a concentração de copolímero \%(PES/PDMS) na superfície das amostras em função do grau de estiramento $\alpha$ para profundidade da análise por XPS de 50 e de $25 \AA$. Como se vê,o estiramento acarreta uma queda da segregação superficial do copolímero. Analisando a concentração me-

b) $\mathrm{CR}+1 \% \mathrm{PES} / \mathrm{PDSM}(44000 / 2500)$

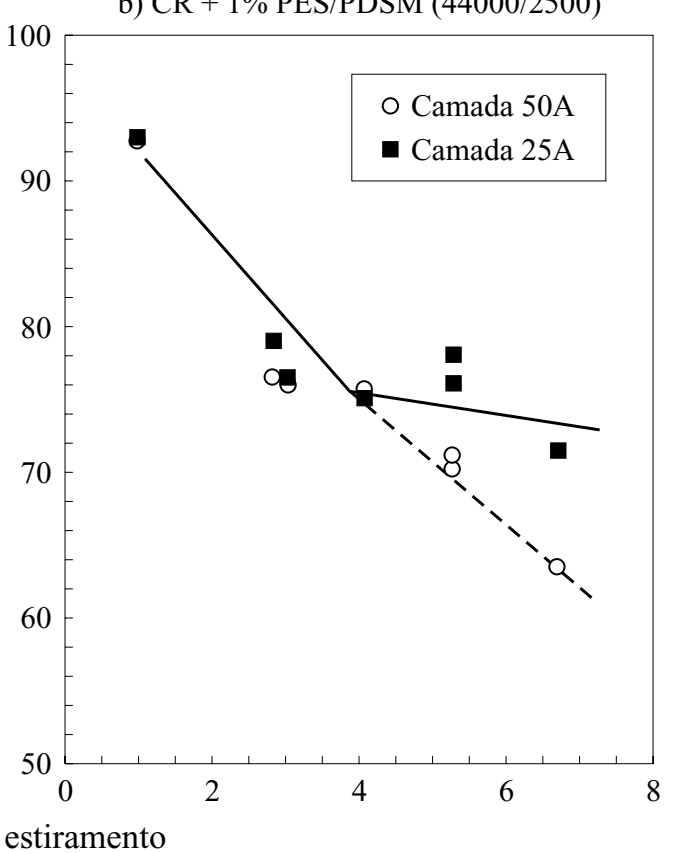

Figura 2. Concentração de copolímero PES/PDMS na superfície das misturas: a) CR+1\%PES/PDMS(3500/2500) e b) CR+1\%PES/ PDMS(44000/2500) em função do grau de estiramento $\alpha$ para profundidades de análise por XPS de 50 e $25 \mathrm{~A}$. 
dia na camada de $50 \AA$ (pontos redondos), vemos que o estiramento a 5 vezes (o que leva a aumento da área da superfície do filme a 2,2 vezes) leva à diminuição de parte de copolímero de $88 \%$ até $67 \%$ para copolímero com curto bloco rígido (mistura a), e de $93 \%$ até $70 \%$ para o copolímero com bloco rígido longo (mistura b). A maioria dos pontos experimentais para camada superficial mais fina $(25 \AA)$ ficam mais elevados do que para camada de $50 \AA$. Isso significa que, apesar de queda de quantidade de revestimento copolimérico no processo de estiramento, a concentração de copolímero aumenta em direção à superfície.

Para explicar as mudanças no grau de segregação de copolímero convém empregar o parâmetro $K(\alpha)$ a relação entre a concentração superficial de algum componente da mistura medida na amostra estendida $\mathrm{C}(\alpha)$ e a concentração medida na amostra inicial C (1). Mas como essa relação para todos os elementos do componente estudado equivale à relação de um elemento desse componente, podemos escolher um. Para concentração de matriz elástica $\mathrm{CR}$ antes e depois de estiramento convém usar elemento cloro:

$$
\mathrm{K}=\mathrm{C}_{\mathrm{Cl}}(\alpha) / \mathrm{C}_{\mathrm{Cl}}(1)=\mathrm{C}_{\mathrm{CR}}(\alpha) / \mathrm{C}_{\mathrm{CR}}(1)
$$

Em outras palavras, este parâmetro mostra quantas vezes a concentração da matriz elástica na superfície

a) $\mathrm{CR}+1 \% \mathrm{PES} / \mathrm{PDSM}(3500 / 2500)$

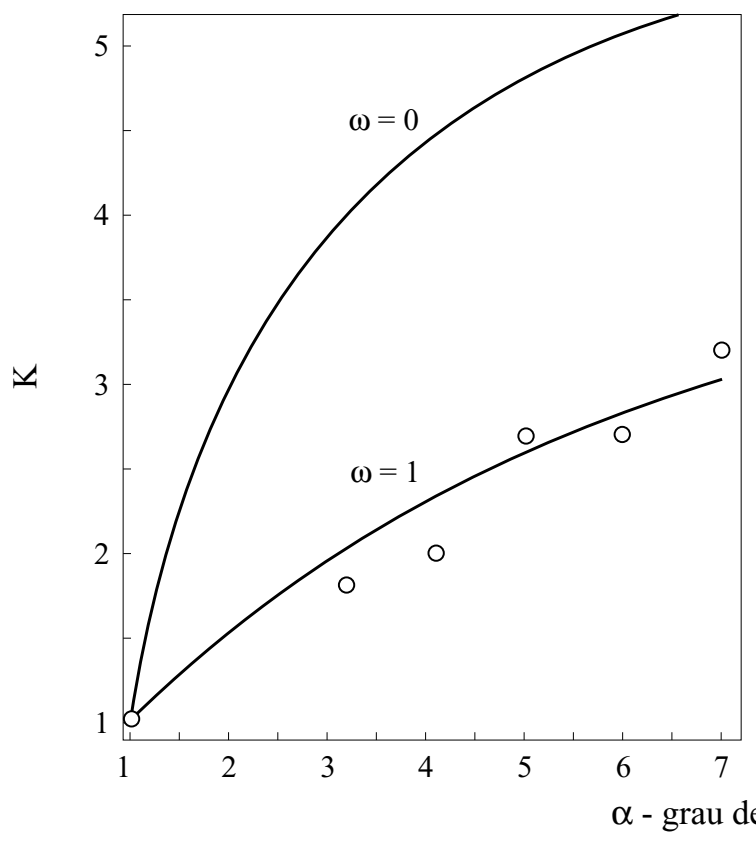

do polímero estendido é maior do que no polímero inicial.

Na Figura 3, os círculos pequenos indicam a dependência do parâmetro $\mathrm{K}$ em relação ao grau de estiramento, obtida por meio da análise por XPS de amostras estendidas (camada de $50 \AA$ ). A Figura $3 a$ é para a composição do copolímero com o PES curto (3500) e a Figura 3b é para a composição com o PES comprido (44000). Vemos que em ambos os casos o estiramento acarreta um aumento bem grande do sinal do elastômero na camada superficial: quando o estiramento é de 7 vezes, num caso o CR torna-se 3 vezes maior e, em outro caso, 5 vezes maior do que era antes de ser estendido. Para esclarecer a questão se o copolímero estende-se junto com o elastômero ou, ao contrário, não reage à extensão, comparemos o parâmetro experimental K (obtido de XPS) com o estiramento teórico para diversos modelos de extensão da camada superficial.

A camada superficial das misturas PC+PES/ PDMS esquematicamente está apresentada na Figura 4a. Se a deformação de toda a amostra é, no seu todo, homogênea, o estiramento da camada superficial seguirá exatamente a da CR matriz (Figura $4 b$ ). Neste caso, uma fração da área que faz parte da matriz CR descoberta, continuará a ser invariável,

b) $\mathrm{CR}+1 \% \mathrm{PES} / \mathrm{PDSM}(44000 / 2500)$

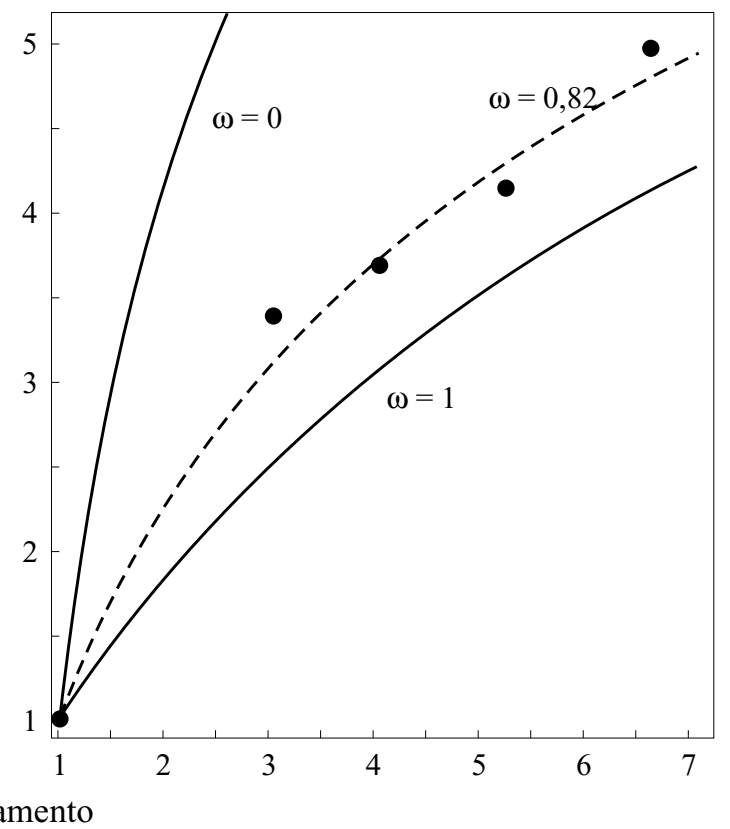

Figura 3. Dependência do parâmetro K (relação de concentração da matriz elástica na superfície do polímero estendido e polímero inicial) do grau de estiramento $\alpha$ para: a) composição do copolímero com o PES curto (3500) e b) composição com o PES comprido (44000). Pontos redondos - os valores experimentais, obtidos por XPS; as curvas - cálculos teóricos para os modelos $\omega=0$ (camada superficial rígida) e $\omega=1$ (deformação homogênea) . 
ao mesmo tempo que a espessura da camada será $\mathrm{t}=\mathrm{t}_{0} \gamma$, em que o índice " 0 " diz respeito à amostra inicial, não estendida, e $\gamma$ significa o grau de contração da espessura da amostra.

Outro caso extremo a que vamos denominar modelo da camada rígida (Figura 4c), baseia-se na suposição de que o copolímero não reage à extensão da matriz e toda a superfície nova, no processo de extensão, é formada pelo CR.

Todos os casos intermediários entre a deformação homogênea e o modelo de camada superficial rígida podem ser descritos formalmente introduzindo-se o parâmetro "grau de deformação da camada superficial" sob o estiramento da matriz: $\alpha^{\omega},(0<=\omega<=1)$, w é o parâmetro que mostra até que grau o estiramento da camada superficial segue o estiramento da matriz.

Retornemos à Figura 3, isto é, ao gráfico da dependência do conteúdo de CR (matriz elástica), na superfície modificada pelo copolímero PES/ PDMS, do grau de estiramento das amostras. As curvas-modelo para $K(\alpha)$ são apresentadas no diagrama junto com os pontos experimentais. As linhas contínuas dizem respeito a dois casos extremos: $\omega=0$, isto é, modelos de camada superficial rígida $\mathrm{e}$ $\omega=1$, isto é, modelo de deformação homogênea. Em ambos os casos, supunha-se que a espessura da cobertura, antes do estiramento, equivalia a $50 \AA$.

Dos diagramas da Figura 3 se deduz que o modelo de camada rígida $(\omega=0)$ é incapaz de descrever resultados experimentais, quer dizer que os domínios de copolímero, apesar de propriedades mecânicas diferentes do elastômero, deforma-se junto com a matriz elastomérica.

A conduta do copolímero $3500 / 2500$, isto é, do copolímero com um bloco rígido curto, é bem descri-
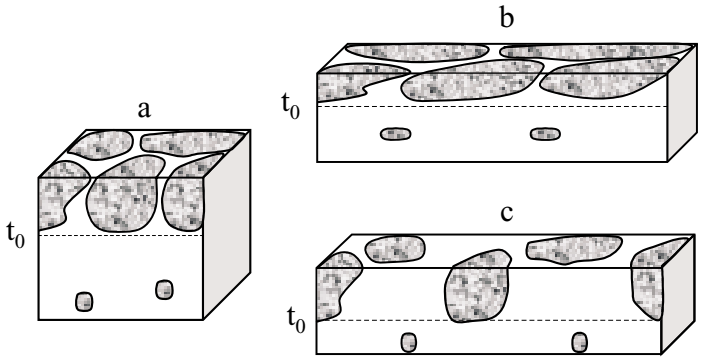

Figura 4. A camada superficial das misturas CR+PES/PDMS: a) antes do estiramento, b) estendida de modo homogêneo, $\omega=1 \mathrm{c}$ ) estendida com domínio de copolímero inflexível, $\omega=0 ; \mathrm{t}$ profundidade de camada de copolímero, s - área da superfície coberta pelo copolímero. ta pelo modelo de deformação homogênea $(\omega=1)$, o que significa que a camada desse copolímero segue o estiramento de matriz elastomérica.

No caso do copolímero com um bloco rígido longo os pontos experimentais se dispõem acima da curva teórica $(\omega=1)$, provavelmente a deformação da superfície modificada acontece com pequeno atraso relativo ao estiramento da matriz. O melhor resultado da adaptação da curva teórica e experimental se obtém sob $\omega=0,82$. Por exemplo, quando a matriz elástica se estende 3 vezes, a cobertura com o copolímero se estende 2,5 vezes.

A informação adicional sobre como o revestimento copolimérico acompanha o estiramento da matriz elastomérica pode ser obtida com a análise mais detalhada dos dados de XPS, obtidos sob diversos ângulos de análise (Figura 2, camada 25 e $50 \AA)$. Se a parte superficial formada do copolímero, sendo absolutamente inflexível, não se estendesse junto com a matriz elástica, a sua espessura não diminuiria, e na analise angular, da mesma forma que nas amostras não estendidas, não haveria diferença no conteúdo do copolímero. No caso de outro modelo do estiramento, o estiramento do modo homogêneo, o perfil das concentrações, de acordo com a profundidade, se achata no sentido vertical. Neste caso, os maiores ângulos de análise da amostra estendida (profundidade de análise $25 \AA$ ) devem proporcionar os valores maiores de concentrações de copolímero. Da Figura 2a vemos que o copolímero com bloco rígido curto tem um gradiente forte de concentração em todas as amostras estiradas, o que significa que o revestimento de copolímero estende-se com a matriz elastomérica desde o inicio do estiramento. Mas o copolímero com o bloco rígido longo (Figura $3 b$ ) não tem diferença de conteúdo nas camadas 25 e $50 \AA$ até o estiramento a 5 vezes. Isso pode significar que sob deformações pequenas (3-4 vezes) o copolímero não reage à extensão e só sob deformação forte (mais que 5 vezes) o copolímero começa a se estender.

Desta maneira, apesar de uma queda de quantidade de copolímero na superfície com estiramento, observado na Figura 2, podemos constatar que o revestimento copolimérico é capaz de estirar-se junto com a matriz elastomérica. Sendo que o copolímero com um bloco rígido curto acompanha exatamente o estiramento da matriz, ao passo que o 
copolímero com um bloco rígido comprido se atrasa um tanto e se estende um tanto menos. Essa diferença em comportamento de dois copolímeros é perfeitamente lógica do ponto de vista da estrutura da molécula.

Para entender o mecanismo de estiramento do copolímero na superfície de policloropreno, estudamos as mudanças de composição dos blocos PDMS e PES com a deformação.

$\mathrm{Na}$ Figura $5 \mathrm{~b}$ estão apresentadas as linhas do oxigênio da composição inicial CR+ PES(44000)/ PDMS, da mesma amostra estendida de 3, 4 e 5 vezes, e, para comparação, o espectro de PES puro. Como no CR o oxigênio inexiste, neste caso teremos a sobreposição dos picos dos dois blocos: o oxigênio de PDMS e o oxigênio de PES. À Figura 5a é apresentada a dependência entre relação de dois blocos PDMS/PES (através da relação Si-S) e grau de estiramento. Vê-se que, com o estiramento, observa-se um forte empobrecimento da superfície pela siloxano, que se faz acompanhar de uma redução quase à metade da relação $\mathrm{Si} / \mathrm{S}$. Isto significa que, no processo de extensão, se opera uma reorientação dos blocos do copolímero. Na amostra inicial, conforme já dissemos acima, o copolímero estava orientado com o bloco PDMS em direção à superfície (por força da sua energia mais baixa). No processo de estiramento, a molécula

a) PES/PDSM (44000/2500)

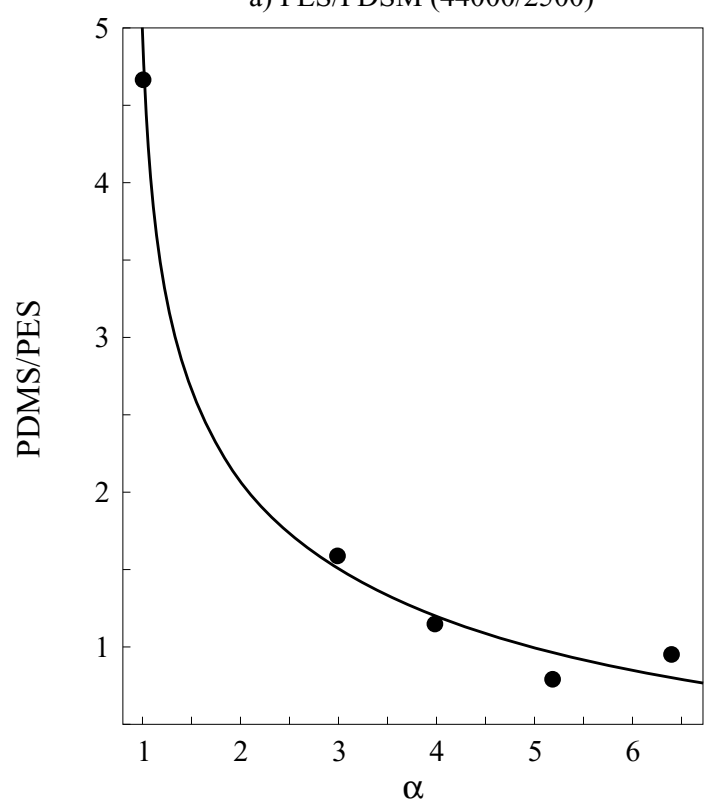

se realinha ao longo do eixo do estiramento e PES aparece na superfície. O mesmo processo é observado no espectro do oxigênio (Figura 5b): na amostra inicial predomina o oxigênio PDMS; o grupo O-Ph só se vê como um ombro fraco da linha. Com o estiramento, a contribuição de PES para a linha Ols aumenta, razão por que aumenta a intensidade relativa do pico $\mathrm{O}=\mathrm{S}$.

Provavelmente a reorientação dos blocos é o mecanismo que permite ao copolímero (com propriedades mecânicas de estado vítreo) seguir o estiramento do elastômero até 5-7 vezes. Esse efeito só pode ser observado na superfície das misturas com um bloco ativo na superfície, por que as macromoléculas da camada superficial dessas misturas, diferentemente das moléculas da massa, são orientados verticalmente. As cadeias flexíveis de siloxano estão dobradas na superfície de tal maneira, que siloxano forma a camada superficial, e polisulfona, ligado nas extremidades do siloxano, fica por baixo. Com o estiramento a molécula se desdobra ao longo de eixo de extensão, acompanhando a extensão da matriz elastomérica.

No copolímero contendo o bloco rígido curto $(\mathrm{CR}+1 \%(3500 / 2500)$ não foram observadas as mudanças significativas na correlação $\mathrm{Si} / \mathrm{S}$ e nem no pico do oxigênio. A explicação pode ser que na camada superficial dessas misturas tem muito mais

b) Linha $\mathrm{O} 1 \mathrm{~s}$

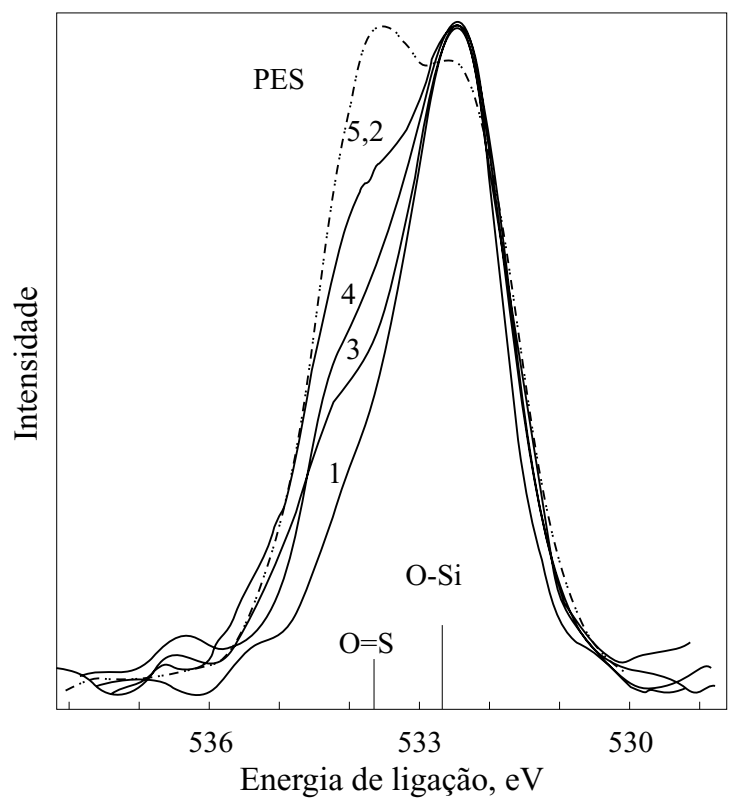

Figura 5. a) Dependência entre relação de dois blocos PDMS/PES e grau de estiramento $\alpha$ para composição PCP+1\%PES/PDMS (44000/ $2500)$, b) as linhas do oxigênio da composição inicial, da mesma amostra estendida de 3, 4 e 5 vezes e, para comparação, do PES puro. 
siloxano e o estiramento passa sem forte reorientação dos dois blocos, ou então, que XPS não fica tão sensível à orientação de blocos de copolímeros.

\section{Conclusões}

A camada superficial do elastômero com superfície modificada pelo copolímero PES/PDMS no processo de estiramento até diferentes graus foi estudada através do método de XPS. Foi estabelecido que no caso de copolímero com bloco de PES curto (bloco rígido), o copolímero na camada superficial estira-se simultaneamente com CR. Mas o cloropreno modificado com copolímero com bloco rígido comprido, o copolímero não consegue acompanhar o estiramento do elastômero e se atrasa um tanto. A reorientação dos blocos de copolímero, observado por XPS, provavelmente é o mecanismo que permite ao copolímero (com propriedades mecânicas de estado vítreo) seguir o estiramento do elastômero até 5-7 vezes.

\section{Agradecimentos}

Ao Conselho Nacional de Desenvolvimento Científico e Tecnológico (CNPq).

\section{Referências Bibliográficas}

1. Affrossman, S. ; Bertrand, P.; Hartshorne, M.; Kiff, T.; D. Leonard, R. A. Pethrick, and R. W. Richards Macromolecules, 29, 5432-5437 (1996).

2. Gorelova, M. M.; Levin Yu, V.; Pertsin, A. I. - Macromol. Chem., Macromol. Symp. 44, p. 317-326 (1991).

3. Pertsin, A. J.; Gorelova, M. M.; Yu. Levin, V.; Makarova, L. I. - J.Appl.Polym.Sci, v.45, 11951202 (1992).

4. Gorelova, M. M.; Pertsin, A. I.; Yu. Levin, V.; Makarova, L. I.; Filimonova, L. V. - J. Appl. Polym. Sci., v. 45, 2075-2078 (1992).

5. Jin Zhao, Rojstaczer, S. R.; Chen, J.; Xu, M.; Gardella, J. A. - Macromolecules, 32, 455-461 (1999).

6. Shard, A. G.; Davies, M. C.; Li, Y. X.; Volland, C.; Kissel, T. - Macromolecules, 30, 30-51-3057 (1997).
7. Gorelova, M. M.; Pertsin, A. J.; Muzafarov, A. M.; Gritsenko, O. T.; Vasilenko, N. G. - J. Appl. Pol. Sci., v. 55, 1131-1135 (1995)

8. Chen, X.; Gardella, J. A. - Macromolecules, 27, 33633369 (1994)

9. Milintchouk, A. V.; Gorelova, M. M.; Muzafarov, A. M.; Nikiforov, A. P. - in the book "The radiation resistance of polymeric materials in the space environmental ", Moscow, NIITEChiM, (1992).

10. Gorelova, M. M.; Pertsin, A. J.; Volkov, I. O.; Filimonova, L. V.; Obolonkova, E. S. - J. App. Pol. Sci., v. 60, 363-370 (1996).

11. Gorelova, M. M.; Pertsin, A. J.; Volkov, I. O.; Sanches, N. B. and Gomes, A. S. - J. App. Pol. Sci., v. 69, 23492356 (1998).

12. Brigs, D. - "Surface analysis of polymers by XPS and static SIMS", Cambridge University Press, New York (1998).

13. Beamson, G. \& Briggs, D. - "High resolution XPS of organic polymers; the Scienta ESCA300 dataabse”, Cambridge University Press, New York (1998).

14. Sabbatini, L. Zambonin, P. G. - "Surface characterization of advanced polymers", Wienheim, Germany, New York, (1993).

15. Volkov, I. O.; Gorelova, M. M.; Pertsin, I. O.; Filimonova, L. V.; Torres, M. A. P. R.; Oliveira, C. M. F. - J. App. Pol. Sci.,v. 68, 517-522 (1997).

16. Volkov, I. O.; Gorelova, M. M.; Pertsin, A. I.; Filimonova, L. V.; Torres, M. A. R.; Oliveira, C. M. F. - Vysokomolyarnye Soedineniya. Ser. A, Vol. 40, N9, 1474-1480 e Polymer Science, Ser.A, Vol.40, N9, 920-924 (1998).

17. Baricia, F. L.; Soares, B. G.; Gorelova, M.; Cid, J. Journal of Applied Polymer Science, V.74, 14241431 (1999).

18. Barcia, F. L.; Soares, B. G.; Gorelova, M. M. e Cid, J. Polímeros: Ciência e Tecnologia, , N2, 30-36 (1999)

19. Bforman, Don - cap.13, ed.Maurice Morton, "Rubber Technology", Van Nostrand Reinold Company, New York (1973).

Recebido: 22/03/99 Aprovado: 16/12/99 